\title{
Double-layer structure in polar mesospheric clouds observed from SOFIE/AIM
}

\author{
Haiyang Gao ${ }^{1,2}$, Gordon G. Shepherd ${ }^{3}$, Yuanhe Tang ${ }^{4}$, Lingbing Bu ${ }^{1,2}$, and Zhen Wang ${ }^{1,2}$ \\ ${ }^{1}$ Key Laboratory for Aerosol-Cloud-Precipitation of China Meteorological Administration, Nanjing University of Information \\ Science and Technology, Nanjing, China \\ ${ }^{2}$ School of Atmospheric Physics, Nanjing University of Information Science and Technology, Nanjing, China \\ ${ }^{3}$ Centre for Research in Earth and Space Science, York University, Toronto, Canada \\ ${ }^{4}$ School of Science, Xi' an University of Technology, Xi' an, China \\ Correspondence to: Haiyang Gao (gaohy@ nuist.edu.cn)
}

Received: 31 October 2016 - Revised: 6 February 2017 - Accepted: 13 February 2017 - Published: 28 February 2017

\begin{abstract}
Double-layer structures in polar mesospheric clouds (PMCs) are observed by using Solar Occultation for Ice Experiment (SOFIE) data between 2007 and 2014. We find 816 and 301 events of double-layer structure with percentages of 10.32 and $7.25 \%$ compared to total PMC events, and the mean distances between two peaks are 3.06 and $2.73 \mathrm{~km}$ for the Northern Hemisphere $(\mathrm{NH})$ and Southern Hemisphere (SH) respectively. Double-layer PMCs almost always have less mean ice water content (IWC) than daily IWC during the core of the season, but they are close to each other at the beginning and the end. The result by averaging over all events shows that the particle concentration has obvious double peaks, while the particle radius exhibits an unexpected monotonic increase with decreasing altitude. By further analysis of the background temperature and water vapour residual profiles, we conclude that the lower layer is a reproduced one formed at the bottom of the upper layer. 56.00 and $47.51 \%$ of all double-layer events for the $\mathrm{NH}$ and $\mathrm{SH}$ respectively have temperature enhancements larger than $2 \mathrm{~K}$ locating between their double peaks. The longitudinal anti-correlation between the gravity waves' (GWs') potential energies and occurrence frequencies of double-layer PMCs suggests that the double-layer PMCs tend to form in an environment where the GWs have weaker intensities.
\end{abstract}

Keywords. Atmospheric composition and structure (aerosols and particles; cloud physics and chemistry; middle atmosphere - composition and chemistry)

\section{Introduction}

The mesosphere and lower thermosphere (MLT) region exhibits a balance of processes and is often treated as a separate atmospheric region. An interesting subject in MLT is the temporal changes in thermal structure and atmospheric composition largely induced by atmospheric waves including gravity waves (GWs), thermal tides, lunar gravitational tides and planetary waves (PWs) (see, e.g., Fritts, 1984; McLandress et al., 1996; Pertsev et al., 2015; Liu et al., 2015). These changes can also have an impact on the distributions of natural phenomena occurring in the MLT that generate some small-scale structures such as multiple-layer structures. The nightglows of $\mathrm{OH}, \mathrm{O}\left({ }^{1} \mathrm{~S}\right)$ green line and $\mathrm{O}_{2}\left(\mathrm{~b}^{1} \sum_{\mathrm{g}}^{+}\right)$ (0-0) band, observed by the Wind Imaging Interferometer (WINDII), show the obvious double-peaked structures in some of their data. These may be caused by the GWs, disturbance of the atomic oxygen or mesospheric temperature inversion layers (MILs) or may be associated partly with the diurnal tide (Melo et al., 2000; Liu and Shepherd, 2006). For $\mathrm{OH}$ dayglow measured by the Sounding of the Atmosphere using Broadband Emission Radiometry (SABER), a longterm stable double-layer structure is found to be caused by photochemical processes involving $\left[\mathrm{O}_{3}\right]$ and modulated by temperature and $[\mathrm{H}]$ (Gao et al., 2015). Additionally, there is often a multiple-layer structure occurring in the polar mesosphere summer echoes (PMSEs) (Röttger, 1994; Klostermeyer, 1997; Rüster et al., 2001; Dubinskii and Popel, 2012). Such fine structures can be at least partially related to the GWs, ice particles and wind velocity by comparing the mea- 
surements and results of models (see, e.g., Hill et al., 1999; Hoffmann et al., 2005, 2008; Li et al., 2016).

Polar mesospheric clouds (PMCs), also called noctilucent clouds (NLCs), are extremely sensitive to background atmospheric temperature, moisture and mesospheric dynamical processes; therefore, they have been considered as a tracer for long-term changes in the MLT (see, e.g., Thomas et al., 1989; Hervig and Stevens, 2014; DeLand and Thomas, 2015), although no statistically significant trends in NLC characteristics are observed from the ground at middle and subpolar latitudes $\left(50-64^{\circ} \mathrm{N}\right)$ (see, e.g., Romejko et al., 2003; Dalin et al., 2006; Pertsev et al., 2014). Accordingly, the vertical changes in background atmospheric structure should also result in variations of PMCs' vertical distributions such as a layered structure similar to that for airglow and PMSEs. Lidar is very capable of detecting these small-scale vertical structures in NLCs. Baumgarten et al. (2012) observed a few double-layer structures and periodic enhancements in brightness in NLCs which were embedded in a wider layer most of the time. Kaifler et al. (2013a) present small-scale structures including multi-layer structure and waves in NLCs by the ALOMAR lidar with a temporal resolution of $30 \mathrm{~s}$. The results show that the NLC formed by the small-scale waves excited by breaking GW can be used to monitor the dynamical processes that lead to its existence. Kaifler et al. (2013b) provides statistics of double layers by using two large data sets from ALOMAR Rayleigh/Mie/Raman lidar in northern Norway and Davis Rayleigh/Raman lidar in Antarctica. They find multiple layers during $9 \%$ of all NLC observations with vertical separations of double layers between 1.5 and $3.0 \mathrm{~km}$. The NLCs characteristics on short timescales are concluded to be presumably impacted by small-scale waves in the vicinity of the clouds. Dubinskii and Popel (2012) use a model of dusty plasma structures to modulate the particle concentration profiles for demonstrating the formation of the layered structure. Those varying profiles in time series indicate that the lower layer has a faster sedimentation speed by absorbing almost all water vapour on the path, while the upper layer moves more slowly. Other possibilities such as two different cloud systems advecting within a region of vertical wind shear, or temperature enhancement in the region of NLCs can also produce layered structure (see, e.g., Fogle and Haurwitz, 1966). In fact, the formation of layering process may be caused by a dominant mechanism or a variety of mixed mechanisms. These sporadic multi-layer PMCs lead to the relative lack of observational data for them, therefore increasing the difficulty of a comprehensive and systematic study on this phenomenon.

While observations from ground-based instruments provide data sets with excellent time resolution on a local scale, satellite-borne instruments extend the detection range to a global scale. The Solar Occultation for Ice Experiment (SOFIE), one of the instruments on board the Aeronomy of Ice in the Mesosphere (AIM) satellite launched on 25 April 2007, provides outstanding data with high vertical resolution
(Russell III et al., 2009; Hervig et al., 2009). The purpose of this research is to report on the properties and vertical structure of double-layer PMCs found in the SOFIE observations, as well as discuss the possible explanations for those complex profiles.

\section{Data and method for identifying double-layer structure}

\subsection{SOFIE data}

SOFIE performs satellite solar occultation measurements to determine vertical profiles of PMCs' properties as well as the surrounding temperature, pressure, and abundance of $\mathrm{H}_{2} \mathrm{O}$. It observes 15 sunrise solar occultations at a latitude range of 65 to $86^{\circ} \mathrm{N}$ in the $\mathrm{NH}$ and 15 sunset solar occultations at latitudes from 63 to $78^{\circ} \mathrm{S}$ in the $\mathrm{SH}$. The field of view (FOV) is about $1.5 \mathrm{~km}$ vertical $\times 4.3 \mathrm{~km}$ horizontal. Detectors are sampled at $20 \mathrm{~Hz}$, which corresponds to $\sim 145 \mathrm{~m}$ vertical spacing, or roughly 10 times over-sampling. The line of sight (LOS) through the PMC layer at $83 \mathrm{~km}$ is $\sim 290 \mathrm{~km}$. The data of version 1.3 with more precise temperatures are used in this work. The profiles in this version have an altitude range of $15-95 \mathrm{~km}$, with the finest vertical resolution of less than $1 \mathrm{~km}$ (Hervig et al., 2009; Marshall et al., 2011; Stevens et al., 2012).

\subsection{Extraction of double-layer PMCs}

In total, SOFIE has observed 7907 PMC events for the NH and 4153 PMC events for the SH from all PMC seasons during eight years from 2007 to 2015 . This work uses the ice volume density $\left(V_{\text {ice }}\right.$ in units of $\mu \mathrm{m}^{3} \mathrm{~cm}^{-3}$ ) profiles and their gradients search for the events with double-layer structures, since the $V_{\text {ice }}$ is proportional to PMC extinctions at infrared (IR) wavelengths $(\lambda>2.5 \mu \mathrm{m})$, which is retrieved directly from SOFIE atmospheric transmission measurements (Gordley et al., 2009; Hervig et al., 2009). In order to extract double-layer events from all $V_{\text {ice }}$ profiles, there are some restrictions on the searching process. Firstly, the ice water content (IWC, in units of $\mathrm{g} \mathrm{km}^{-2}$, which is the vertical integral of ice mass density) for selected profiles should be larger than $5 \mathrm{~g} \mathrm{~km}^{-2}$, which has been used as the dividing line between cloudy and no PMCs (Hervig et al., 2015). Secondly, the profiles with at least two peaks can be temporarily retained by searching the inflection points from the discrete derivative curves for $V_{\text {ice }}$ profiles. Thirdly, each peak of a selected profile should be greater than its corresponding error threshold, which is a combination of two parts. One part is the mean value obtained by averaging all peaks from the weak PMC $V_{\text {ice }}$ profiles (IWC $<5 \mathrm{~g} \mathrm{~km}^{-2}$ ) during the adjacent 3 days, while the other part is their standard deviation. The aim of this step is to remove those unidentified peaks which may be caused by uncertainties from detection sensitivity and the onion peeling retrieval algorithm. Then we can obtain those 
$V_{\text {ice }}$ profiles with only two identified peaks. In fact, we find a few profiles with multiple peaks $(>2)$ through these processes, but their number is not sufficient for statistics, so they are excluded in this work. Next, considering the basic data limitations (vertical resolution of $\sim 1 \mathrm{~km}$ ), the profiles with a distance of less than $2 \mathrm{~km}$ between two peaks need to be removed from our analysis. Lastly, we need to define a modulation index for describing the contrast between two peaks and trough of each $V_{\text {ice }}$ profile as follows:

$M_{\mathrm{p}-\mathrm{t}}=\frac{\left(V_{u \text {-peak }}+V_{l \text {-peak }}\right) / 2-V_{\text {trough }}}{\left(V_{u \text {-peak }}+V_{l \text {-peak }}\right) / 2+V_{\text {trough }}}$

where $M_{\mathrm{p}-\mathrm{t}}$ is the modulation of peak to trough, and $V_{u \text {-peak }}$, $V_{l \text {-peak }}$ and $V_{\text {trough }}$ denote the ice mass densities of the two peaks and the trough between them respectively. The profiles with modulation greater than 0.2 are chosen for analysis. Eventually, these selected profiles satisfying the above requirements can be identified as a double-layer structure.

Figure 1 provides a typical example of $V_{\text {ice }}$ profile with a double-layer structure. The red curve denotes the ice volume density profile for orbit number 3926 on 14 January 2008 in the $\mathrm{SH}$. The blue solid line represents the mean $V_{\text {ice }}$ for peaks of background weak PMCs, while both dashed lines are 1 standard deviation. Both the weak peaks in the ranges of $86.5-88.5 \mathrm{~km}$ and $79.0-81.0 \mathrm{~km}$ respectively are removed according to the above algorithm, since they are not large enough to exceed the uncertainty limitation. Thus, only peak 1 at $84.4 \mathrm{~km}$ and peak 2 at $82.2 \mathrm{~km}$ are filtered out as an identified double-layer structure. By calculation, the distance $\Delta z$ between peaks is $2.4 \mathrm{~km}$, while the full widths at half maximum (FWHMs), as the parameter to quantify cloud thickness $T_{\text {peak-1 }}$ and $T_{\text {peak-2 }}$, are 1.32 and $1.51 \mathrm{~km}$ respectively.

Furthermore, due to varying altitudes of peaks and troughs for single PMC events, some interesting structures may be hidden by simply averaging profiles according to their real altitudes. Thus, in most parts of this paper we rearrange the profiles aligned to the trough altitude. This reorganization of the data can show a clearer layer structure which has been proved to be a very effective method by Baumgarten and Fiedler (2008).

\section{Data analysis and results}

\subsection{General distribution}

Using the searching algorithm mentioned above, we finally obtain 816 and 301 PMC events with double-layer structure from $\mathrm{NH}$ and $\mathrm{SH}$ seasons between 2007 and 2015 respectively. The percentages of these selected events to total 7907 and 4153 PMC events are 10.32 and $7.25 \%$, which are similar to that of previous studies using local time series data (Kaifler et al., 2013b). Both amounts are enough for analysis of the overall statistical characteristics, but they are not enough for analysis of the difference among seasons. Thus,

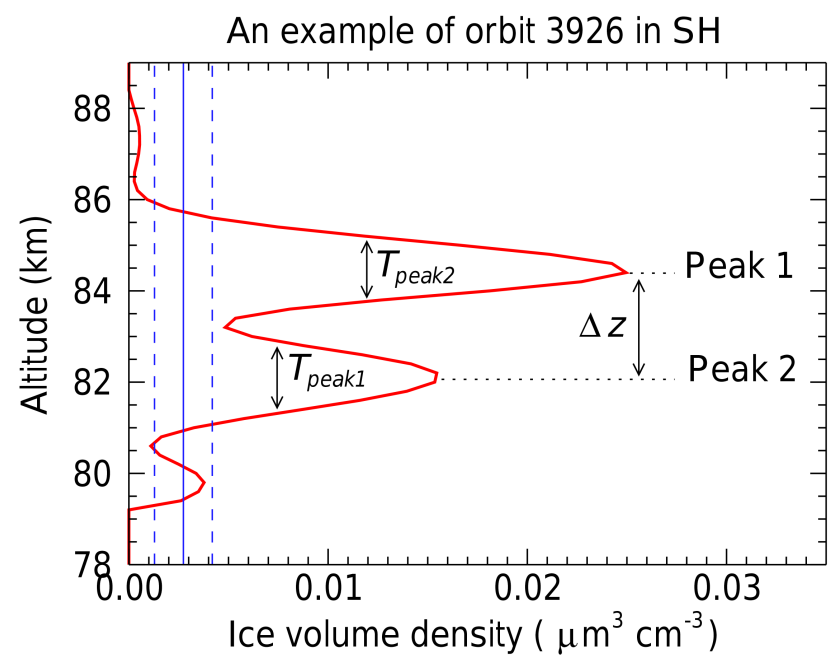

Figure 1. An example for extracting the double-layer event from ice volume density profile (red curve) of orbit number 3926 on 14 January 2008 in the SH. The blue solid line denotes the mean ice volume density for peaks of background weak PMCs, while both dashed lines are 1 standard deviation. $T_{\text {peak-1 }}$ and $T_{\text {peak-2 }}$ represent cloud thickness, while $\Delta z$ is the distance between the identified two peaks.

this work prefers to make a comprehensive analysis using these data as a whole.

All $V_{\text {ice }}$ profiles of double-layer events are aligned to their troughs and rearranged with regard to increasing trough altitudes. We let all trough altitudes be zero, leading to a relative altitude for each trough as the vertical coordinate. The rearranged $V_{\text {ice }}$ profiles are then shown in Fig. 2a for the $\mathrm{NH}$ and $2 b$ for the SH. The event number shown as the horizontal coordinate is a new number for each double-layer event with regard to increasing trough altitude. Although it seems a proxy for the trough altitude, we cannot simply swap event number for trough altitude since some altitudes may correspond to two or more events. The results show that the $V_{\text {ice }}$ in all peaks vary within a wide range of $0.011-0.097 \mu^{3} \mathrm{~cm}^{-3}$ for the NH and $0.009-0.062 \mu \mathrm{m}^{3} \mathrm{~cm}^{-3}$ for the SH. These also indicate that the double-layer structures exist in either strong or weak PMCs. For each $V_{\text {ice }}$ profile, the peak with the most $V_{\text {ice }}$ is defined as the main peak, while the other weaker peak can be considered as the secondary peak. The scatter data in Fig. 2c and d show the real altitudes of the main peaks (red diamonds), secondary peaks (green circles) and troughs (blue dashed curves) respectively. These decentralized distributions indicate that double-layer structures can occur at any PMC altitude. It is also interesting to note that there may be a dependence of the relative position between two peaks on trough altitude especially for the lower altitude. For the $\mathrm{NH}$, when troughs are lower than $81.5 \mathrm{~km}$, the main peaks are mostly located above the troughs. However, at other higher altitudes, the secondary peaks gradually appear above the troughs with increasing trough altitudes. When the troughs 
(a) Ice volume density $\left(\mu \mathrm{m}^{3} \mathrm{~cm}^{-3}\right)$
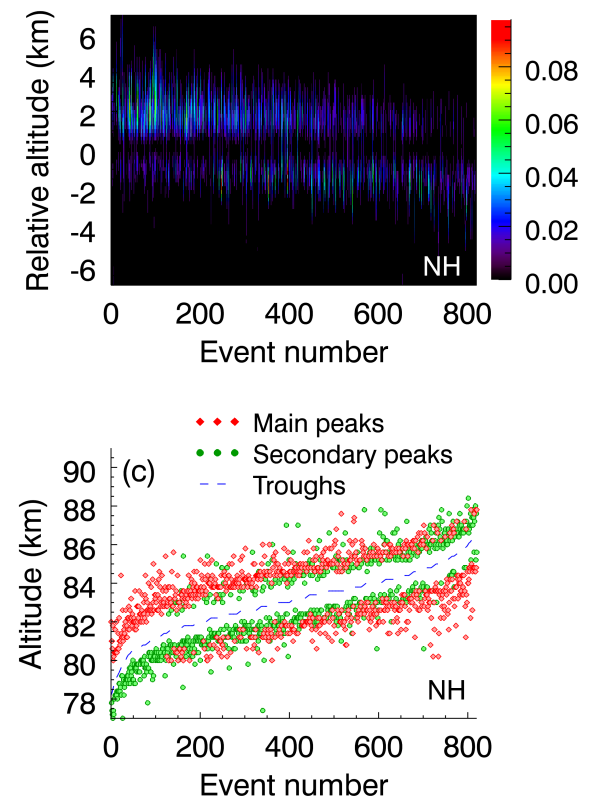

(b) Ice volume density $\left(\mu \mathrm{m}^{3} \mathrm{~cm}^{-3}\right)$
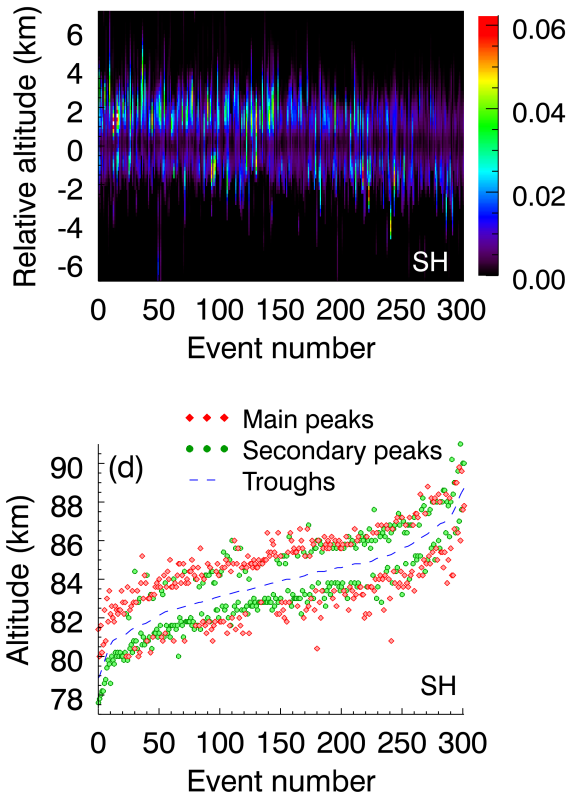

Figure 2. All events with double-layer structure observed by SOFIE from 2007 to 2014. The ice volume density ( $\left.V_{\text {ice }}\right)$ profiles are shown for (a) $\mathrm{NH}$ and (b) SH respectively, and aligned to the troughs between two peaks. The event number is arranged according to increasing altitude of the trough. The real altitudes for peaks (diamonds and circles) and troughs (dashed lines) are shown in (c) and (d). The red diamonds represent the main peak altitudes with the greatest $V_{\text {ice }}$, while the green circles are the secondary peak altitudes.

are higher than about $85 \mathrm{~km}$, the number of secondary peaks above the troughs begin to exceed that of the main peaks. For the $\mathrm{SH}$, the number of secondary peaks above the troughs also has a gradual increase with increasing altitude, but it is always less than the number of main peaks above the troughs. Furthermore, the distances between main peaks and troughs vary with a wider range than that between secondary peaks and troughs.

The distributions of double peak altitudes are important features for vertical structure. Histograms of upper and lower peak altitudes with an interval of $1 \mathrm{~km}$ are shown in Fig. 3a for the $\mathrm{NH}$ and $\mathrm{SH}$ respectively. Some detailed parameters, including the mean value, standard deviation and the standard deviation of the mean, are listed in Table 1. For calculating the mean distance between two peaks (or between peak and trough), it is worth noting that we firstly calculate the distance for each profile and then average all the corresponding distances to get the mean distance. The mean altitudes for upper and lower peaks are 84.64 and $81.58 \mathrm{~km}$ in the $\mathrm{NH}$, while they have higher values of 85.24 and $82.51 \mathrm{~km}$ in the SH. In order to determine the interhemispheric differences, the $t$ tests are implemented for upper peaks and lower peaks respectively. Both significances of $9.21 \times 10^{-7}$ for upper peaks and $1.35 \times 10^{-13}$ for lower peaks are less than 0.05 , which indicates a statistically distinguished differences. Also, the histograms in Fig. 3a show that the most probable altitudes for both the upper and lower peaks of $85 \pm 1 \mathrm{~km}$ and $82 \pm 1 \mathrm{~km}$ in the SH are $1 \mathrm{~km}$ higher than that of $84 \pm 1 \mathrm{~km}$ (a) Upper and lower peak altitude distributions
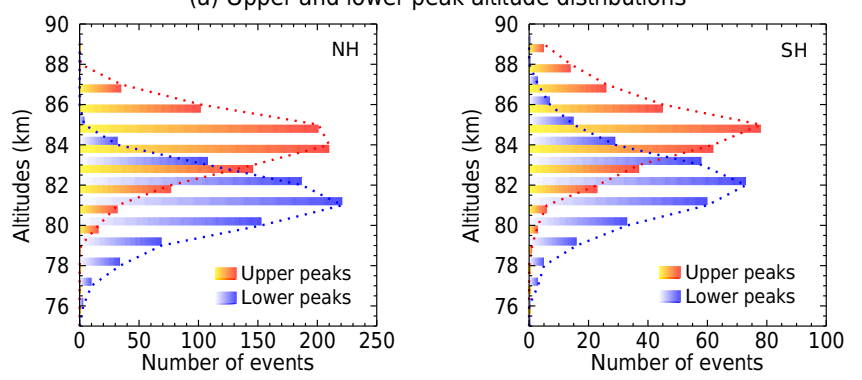

(b) Main and secondary peak altitude distributions
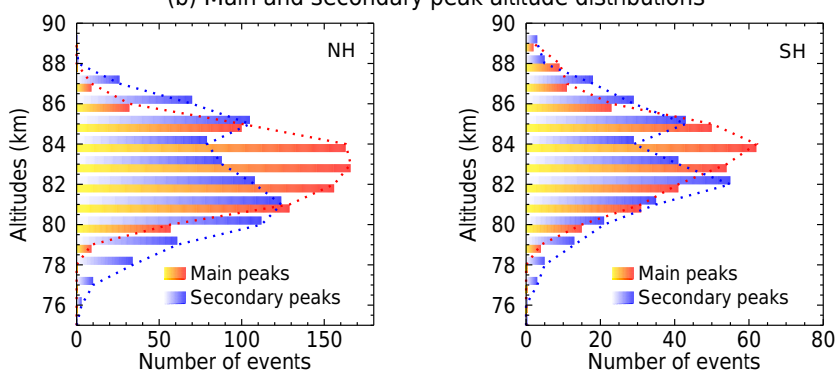

Figure 3. Histograms of peak altitudes with an interval of $1 \mathrm{~km}$. (a) Upper and lower peaks distributions for the $\mathrm{NH}$ and $\mathrm{SH}$. (b) Main and secondary peaks distributions for the NH and SH. The dashed curves are the envelopes for the histograms. 
Table 1. Properties of PMCs with double-layer structure. The mean value, the standard deviation and the standard deviation of the mean (in brackets) are given.

\begin{tabular}{|c|c|c|}
\hline Properties & NH seasons & SH seasons \\
\hline Number of PMC events & 7907 & 4153 \\
\hline Number of double-layer events & 816 & 301 \\
\hline Percentage of double-layer events to all PMC events & $10.32 \%$ & $7.24 \%$ \\
\hline Mean $H_{\text {upper- }} p(\mathrm{~km})$ & $84.64 \pm 1.55(0.05)$ & \\
\hline Mean $H_{\text {upper- } p}(\mathrm{~km})$ & $81.58 \pm 1.66(0.06)$ & $82.51 \pm 1.87(0.11)$ \\
\hline Mean $H_{\text {trough }}(\mathrm{km})$ & $82.99 \pm 1.63(0.06)$ & $83.79 \pm 1.90(0.11)$ \\
\hline$H_{\text {upper- }-p}-H_{\text {lower- }-p}(\mathrm{~km})$ & $3.06 \pm 1.04(0.04)$ & $2.73 \pm 0.79(0.05)$ \\
\hline$H_{\text {upper- } p}-H_{\text {trough }}(\mathrm{km})$ & $1.65 \pm 0.70(0.02)$ & $1.45 \pm 0.55(0.03)$ \\
\hline$H_{\text {trough }}-H_{\text {lower- } p}(\mathrm{~km})$ & $1.41 \pm 0.66(0.02)$ & $1.28 \pm 0.55(0.03)$ \\
\hline Mean $V_{\text {ice-upper- } p}\left(\mu \mathrm{m}^{3} \mathrm{~cm}^{-3}\right)$ & $0.0154 \pm 0.0110(0.0004)$ & $0.0144 \pm 0.0108(0.0006)$ \\
\hline Mean $V_{\text {ice-lower- } p}\left(\mu \mathrm{m}^{3} \mathrm{~cm}^{-3}\right)$ & $0.0126 \pm 0.0099(0.0003)$ & $0.0117 \pm 0.0082(0.0005)$ \\
\hline Mean IWC of double-layer events $\left(\mathrm{g} \mathrm{km}^{-2}\right)$ & $56.60 \pm 37.56(1.31)$ & $45.71 \pm 30.95(1.78)$ \\
\hline Mean modulation & $0.495 \pm 0.177(0.006)$ & $0.486 \pm 0.179(0.010)$ \\
\hline Number of upper main peaks & 509 & 180 \\
\hline Mean $H_{\text {main- } p}(\mathrm{~km})$ & $83.47 \pm 1.76(0.06)$ & $84.11 \pm 2.04(0.12)$ \\
\hline Mean $H_{\text {secondary- } p}(\mathrm{~km})$ & $82.75 \pm 2.55(0.09)$ & $83.64 \pm 2.53(0.15)$ \\
\hline Mean $V_{\text {ice-main- } p}(\mathrm{~km})$ & $0.0181 \pm 0.0122(0.0004)$ & $0.0167 \pm 0.0109(0.0006)$ \\
\hline Mean $V_{\text {ice-secondary- } p}(\mathrm{~km})$ & $0.0098 \pm 0.0063(0.0002)$ & $0.0093 \pm 0.0064(0.0004)$ \\
\hline
\end{tabular}

and $81 \pm 1 \mathrm{~km}$ in the NH. These interhemispheric differences may be attributed to the PMCs' characteristics depending on the background atmospheric conditions (Hervig et al., 2013). We can make a rough comparison with the results from lidar, although there are some potential differences in instruments and local distributions. The mean altitudes of the upper peaks in both the NH and the SH show a very similar magnitude compared with that of $84.34-84.56 \mathrm{~km}$ observed by the ALOMAR lidar $\left(69.28^{\circ} \mathrm{N}, 16.01^{\circ} \mathrm{E}\right)$ and $85.17 \mathrm{~km}$ from the Davis Rayleigh/Raman lidar $\left(68.58^{\circ} \mathrm{S}, 77.97^{\circ} \mathrm{E}\right)(\mathrm{Kai}-$ fler et al., 2013b). However, for the lower peaks, the mean altitude from SOFIE in the NH is $\sim 1.3 \mathrm{~km}$ lower than that of $82.80 \mathrm{~km}$ from ALOMAR lidar, while it is $0.41 \mathrm{~km}$ higher than that of $82.10 \mathrm{~km}$ from Davis lidar in the SH.

From Table 1, it can be seen that the mean distances between the two peaks are $3.06 \mathrm{~km}$ for the $\mathrm{NH}$ and $2.73 \mathrm{~km}$ for the SH respectively. Separately, the mean distance of $1.65 \mathrm{~km}$ from upper peak to trough is slightly greater than that of $1.41 \mathrm{~km}$ from trough to lower peak for the $\mathrm{NH}$. The condition is similar for the $\mathrm{SH}$, where the upper distance of $1.45 \mathrm{~km}$ is slightly greater than the lower distance of $1.28 \mathrm{~km}$. All these three mean distances are greater for the NH than for the SH based on the results of $t$ tests. For comparison, this mean distance between peaks in the NH is wider than that of 1.11-1.75 km observed by the ALOMAR lidar, which has greater vertical resolution and shows values as small as several hundred metres for some individual cases (Kaifler et al., 2013b). The mean distance in the SH shows a similar magnitude compared to the result of $3.07 \mathrm{~km}$ observed by the Davis lidar. Compared with double-layer PMSEs, PMCs have comparable distances with that of $\sim 3 \mathrm{~km}$ from VHF radar obser- vations at Andenes $\left(69^{\circ} \mathrm{N}, 16^{\circ} \mathrm{E}\right)$ (Hoffmann et al., 2005; Rüster et al., 2001). For multiple-layer PMSEs, some finer structures with distances even smaller than $1 \mathrm{~km}$ often appear in the upper part of the PMSE (Lübken et al., 2004). Furthermore, such distances are smaller than those of 3-10 km for near-equatorial double-peaked airglow (Melo et al., 2000; Liu and Shepherd, 2006; Gao et al., 2015). In fact, large-scale vertical disturbances cannot be reflected in the PMCs, since regular PMCs' layers are much thinner than airglow.

Another noteworthy phenomenon is the distribution of main and secondary peaks. The main peaks are mostly located above the secondary peaks. There are $509(62.38 \%)$ upper main peaks for the $\mathrm{NH}$ and $180(59.80 \%)$ upper main peaks for the SH. For the mean altitude, main peaks have a greater value than secondary peaks for both the $\mathrm{NH}$ and $\mathrm{SH}$ based on the results of $t$ tests. However, the dashed envelope lines from Fig. $3 b$ indicate that the altitude distributions of secondary peaks have an asymmetric double-peak structure for both the $\mathrm{NH}$ and $\mathrm{SH}$. These also suggest that secondary peaks can appear in a wider region, while the positions of main peaks are more concentrated.

\subsection{IWC variations with regard to days from summer solstice (DFS)}

IWC is an important indicator for double-layer PMCs as it is for the normal single-peak PMCs. In general, the IWC of PMC has a strong seasonal dependence. Both IWCs of double-layer PMCs (red curves) and of single-peak PMCs (green curves) averaged by 2 days are shown in Fig. $4 a$ and $b$. Both of them are basically larger at the middle toward the 

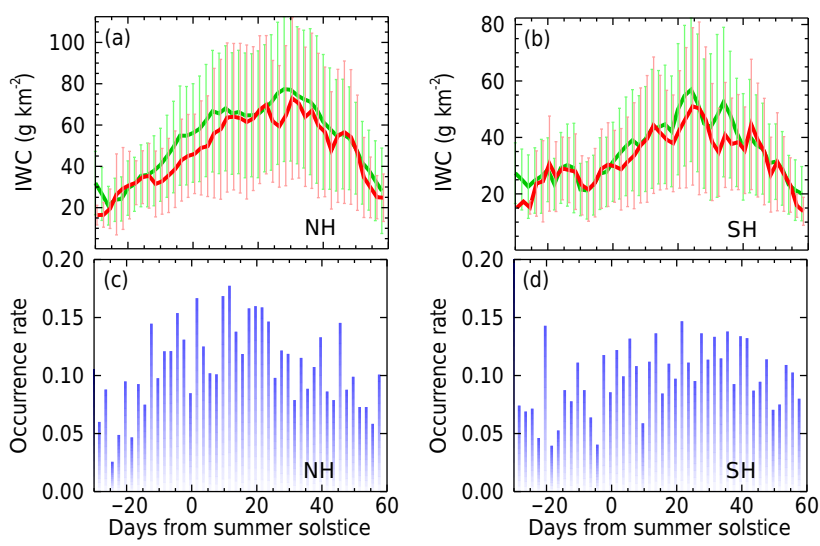

Figure 4. IWC averaged by 2 days for double-layer PMCs (red) and single-peak PMCs (green) in the NH (a) and SH (b) respectively. Error bars denote 1 standard deviation. Occurrence rates of double-layer PMCs as a fraction of all PMC events by 2-day intervals through the $\mathrm{NH}$ and $\mathrm{SH}$ seasons are shown in (c) and (d).

topside than at the two ends. During 0-40 days from summer solstice (DFS) at the core of the season in the $\mathrm{NH}$ or $\mathrm{SH}$, although double-layer PMCs seem to have less mean IWC than those for single peaks with the maximum difference of over $20 \%$, these two IWC curves do not have statistically significant different means with each other based on the results of $t$ tests because of the large standard deviations. Similarly, although they are close to each other at their beginning and ending, this close trend may have some statistical uncertainty since the number of events numbers is low. In fact, IWC has a direct relationship with the surrounding temperature and content of water vapour. The actual situation, however, is much more complicated and will be discussed in the following sections. Figure $4 \mathrm{c}$ and $\mathrm{d}$ show the occurrence rates of doublelayer PMCs to all PMC events by 2-day intervals through the $\mathrm{NH}$ and $\mathrm{SH}$ seasons respectively. Interestingly, the occurrence rates have a similar trend as IWC. The double-layer PMCs prefer to appear in the core of the seasonal variation.

\subsection{Vertical structures}

This section describes the differences of vertical structure between double-layer PMCs and single-peak PMCs. Figure 5 shows the mean profiles of $V_{\text {ice}}$, particle concentration and effective radius as well as their standard deviations of the mean for both kinds of PMCs. Before the averaging process, all profiles of double-layer PMCs are aligned to their trough altitudes, while the profiles of single-peak PMCs are aligned to their peak altitudes. We then raise the green curves up to a calculated distance in order to match the mean real altitude of single peaks to that of the trough for double-layers. Before our analysis, the $t$ tests need to be implemented for examining their significances of differences between the means. The results are shown as some grey translucent rectangular areas onto the subfigures in Fig. 5. The grey areas denote the sig-
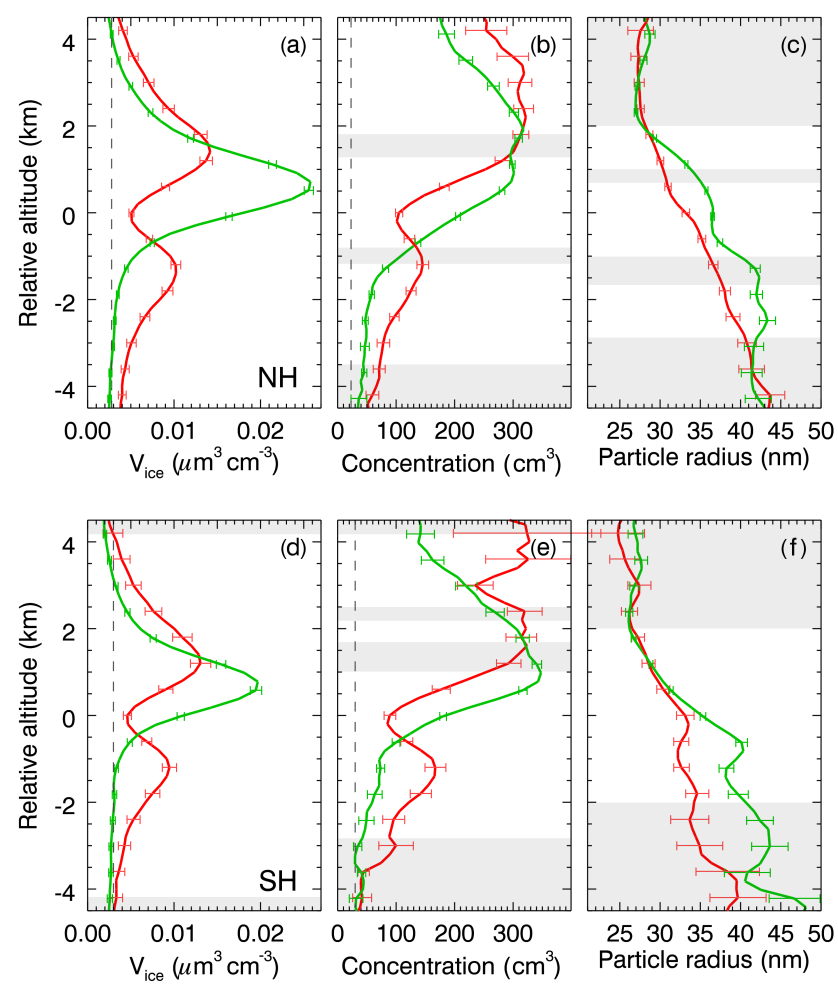

Figure 5. Vertical structures of the $V_{\text {ice }}(\mathbf{a}, \mathbf{d})$, particle concentration (b, e) and effective radius (c, f) for the $\mathrm{NH}$ (upper panel) and $\mathrm{SH}$ (lower panel) respectively. Red profiles are averaged by all doublelayer PMC profiles aligned to their troughs, while green profiles are averaged by single-peak PMC profiles aligned to their peaks. Grey dashed lines represent the thresholds of uncertainty. Error bars show the standard deviation of the mean. The grey translucent rectangular areas show the regions where the significances derived by $t$ tests are larger than 0.05 .

nificances larger than 0.05 , while the white areas with the significances less than 0.05 indicate that the two curves have statistically significant different means with each other at the corresponding altitudes.

For the $\mathrm{NH}$ first, the mean $V_{\text {ice }}$ profile in Fig. 5a shows a clear double-layer structure with modulation of 0.495 calculated by Eq. (1). The main peak with $V_{\text {ice }}$ of $0.0136 \mu \mathrm{m}^{3} \mathrm{~cm}^{-3}$ is located above the secondary peak with $V_{\text {ice of }} 0.0114 \mu^{3} \mathrm{~cm}^{-3}$. There are statistically significant differences between these two profiles at all altitudes. When comparing these two $V_{\text {ice }}$ profiles, the mean $V_{\text {ice }}$ for the main peak is only about half of the $V_{\text {ice }}$ of $0.0258 \mu \mathrm{m}^{3} \mathrm{~cm}^{-3}$ for the single peak. The double-layer profile has a much thicker FWHM of $4.91 \mathrm{~km}$ than that of $1.98 \mathrm{~km}$ for the single-peak profile. However, the FWHM of each layer $(2.38 \mathrm{~km}$ for the upper peak and $2.16 \mathrm{~km}$ for the lower peak) is just slightly thicker than that of the single-peak profile. For the concentration profiles in Fig. 5b, the significances of $\mathrm{NH}$ at most of altitudes are less than 0.05 except for three regions around $1.5,-1.2$ and $-4 \mathrm{~km}$. However, these separate small areas 
can not affect our analysis that the concentration profiles alternate with each other. The concentration of double-layer profiles is more than that of single-peak profile at the cloud top around the position of $4 \mathrm{~km}$, and then they tend to be close to each other with decreasing altitude. When the altitude falls below the upper peak, the concentration of doublelayer profiles begins to decrease sharply and fall below that of a single-peak profile, while the single-peak profile does not show a decrease until its altitude falls below its own peak. When the altitude continues to fall, an interesting phenomenon occurs in that the concentration of double-layer profiles begins to increase again below the trough altitude. This leads to a weak secondary peak appearing in the concentration profile which just corresponds to the region of the lower peak in $V_{\text {ice }}$ profile as shown in Fig. 5a. For the analysis of particle size, we choose the effective radius which can be determined independently of the size distribution using a combination of SOFIE near infrared (NIR) and IR measurements (Hervig et al., 2009). In Fig. 5c, fortunately, these two curves are statistically distinguished from each other in the core regions of $-2-2 \mathrm{~km}$. The most unexpected result is that the mean double-layer radius profile presents a relatively smooth and monotonic increasing trend without any identified double-layer structure relating to decreasing altitude. From the combination of Fig. 5a, b and c, the results suggest that PMC double-layer structure is more sensitive to the particle concentration rather than the effective radius.

For the $\mathrm{SH}$, although the statistically significant areas are slightly fewer than that in the $\mathrm{NH}$, the differences between the corresponding profiles are still significant enough for our analysis at the core of altitudes. For the $V_{\text {ice }}$ profiles in Fig. 5d, the double-layer profile has a modulation of 0.486 . Its main peak with $V_{\text {ice }}$ of $0.0127 \mu \mathrm{m}^{3} \mathrm{~cm}^{-3}$ is greater than half of the single peak with $V_{\text {ice }}$ of $0.0198 \mu \mathrm{m}^{3} \mathrm{~cm}^{-3}$. The shapes for particle concentration and effective radius profiles and their differences between the two structures shown in Fig. 5e and $\mathrm{f}$ have a similar situation as that in the NH. Also, the results suggest that double-layer structure is more sensitive to the concentration rather than the effective radius.

\section{Discussion}

\subsection{Relationship with temperature and water vapour}

In principle, the vertical structure of PMCs can respond to changes in the background atmosphere including temperature, water vapour content, and some dynamic processes. In fact, the generation, growth, maturation and decline of a double-layer PMC are a unified dynamic process with time series based on some previous observations by Lidar or simulations by models (Baumgarten et al., 2012; Kaifler et al., 2013a, b; Dubinskii and Popel, 2012). Satellite observation, however, only provide us with some "snapshots". These snapshots may capture the double-layer structures at
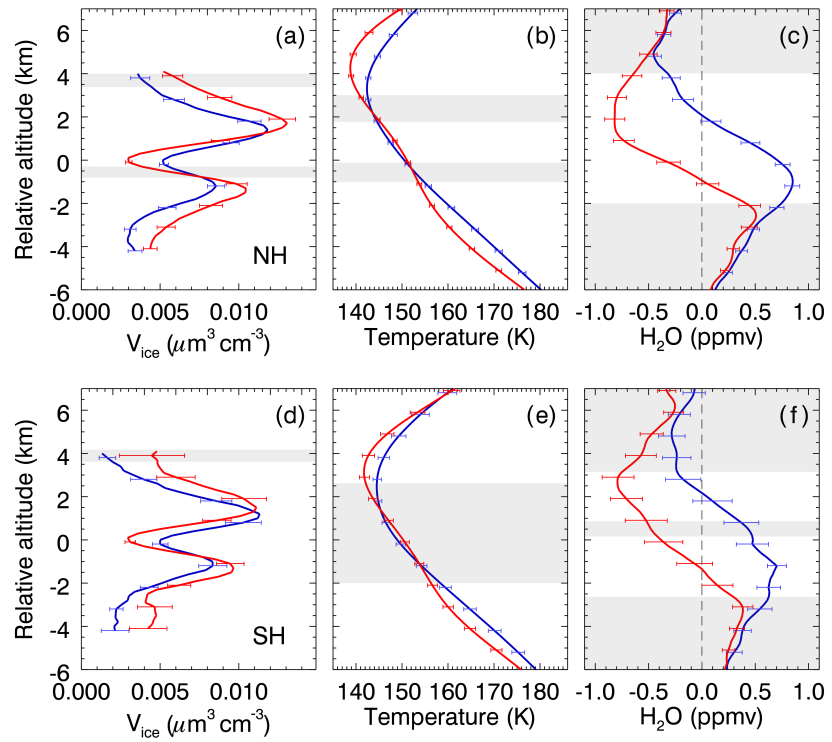

Figure 6. Vertical structures of the $V_{\text {ice }}(\mathbf{a}, \mathbf{d})$, background temperature $(\mathbf{b}, \mathbf{e})$, and water vapour residual $(\mathbf{c}, \mathbf{f})$ for the NH (upper panel) and SH (lower panel) respectively. Red profiles are averaged by the $20 \%$ events of all double-layer PMCs with highest modulations, while blue profiles are averaged by the $20 \%$ events of all double-layer PMCs with lowest modulations. Before the averaging, all profiles are aligned to their troughs. Error bars show the standard deviation of the mean. The grey translucent rectangular areas show the regions where the significances derived by $t$ tests are larger than 0.05

their different life stages. The modulation in Eq. (1) just provides a clue which reflects the relative changing intensity of a double-layer structure. The higher modulation for a $V_{\text {ice }}$ profile indicates the more clearly distinguishable layered structure. Thus, it is instructive to examine the difference between the most distinguishable and less distinguishable cases by means of their modulations. For this purpose, we select the events with the modulations in the top $20 \%$ of results to construct the most distinguishable cases, and the events with the modulations in the bottom $20 \%$ of results to construct the less distinguishable cases. Then the mean $V_{\text {ice }}$ and temperature profiles are calculated for these two groups of cases respectively. Additionally, in order to analyse hydration and dehydration states of a double-layer event, the water vapour residual profiles are calculated for each event. In short, the water vapour residual profile is the difference between the observed and background water vapour profiles, where the positive part means hydration and the negative part means dehydration. The detailed calculation method with SOFIE data has been provided by Hervig et al. (2015). After these processing, all mean profiles are derived and shown in Fig. 6a-f for both the $\mathrm{NH}$ and $\mathrm{SH}$ respectively. Similar to Fig. 5, the $t$ tests need to be implemented for examining their significances of differences between the means of the most and the less distinguishable cases in Fig. 6. The results are shown 
as some grey translucent rectangular areas where the significances are larger than 0.05. The $V_{\text {ice }}$ profiles in Fig. 6a and d have statistically significant different means at almost all altitudes. For the water vapour residual profiles in Fig. $6 \mathrm{c}$ and $\mathrm{f}$, the means are statistically difference at core altitudes $(-3-$ $4 \mathrm{~km})$. For the temperature profiles, the significances larger than 0.05 appear in the region where two curves cross or approach with each other. However, this result does not affect our analysis of the effects of temperature, which will be explained in the following.

For the $\mathrm{NH}$, the mean modulation of the most distinguishable cases shown in Fig. 6a have reached $0.607 \pm$ $0.231(0.019)$, which is much higher than that of $0.349 \pm$ $0.186(0.016)$ for the less distinguishable cases (the numbers in brackets following the standard deviations denote the standard deviation of the mean, the same below). Also, the most distinguishable cases have a slightly greater mean IWC of $58.33 \pm 36.36(2.98) \mathrm{g} \mathrm{km}^{-2}$ and a larger distance of $3.24 \pm$ $1.31(0.11) \mathrm{km}$ than the values of $46.72 \pm 33.57(2.87) \mathrm{g} \mathrm{km}^{-2}$ and $2.59 \pm 0.67(0.06) \mathrm{km}$ for the less distinguishable cases. The mean IWC $\left(56.60 \mathrm{~g} \mathrm{~km}^{-2}\right)$ from all double-layer PMCs listed in Table 1 is just between those of these two kinds of cases. Before the above comparisons of means, we apply the $t$ tests, and the results indicate the significant differences for all of them. When examining the mean temperature profiles in Fig. 6b, we find a very interesting difference in that there is a weak temperature enhancement located around the trough altitude and between two peaks for the most distinguishable cases. These enhancements will be discussed in detail in Sect. 4.3. Although the significances are larger than 0.05 in two small separate regions of $-1.2-0.2 \mathrm{~km}$ and $2-3 \mathrm{~km}$, where two curves cross, we do not use these two areas for analysis. By comparison, the profile of the less distinguishable cases has higher mean temperatures in the most part than the other profile, there is no temperature enhancement, and it has lower temperatures than does the other profile between 0 and $2 \mathrm{~km}$. From the water vapour residual profiles in Fig. 6c, there is a strong dehydration with little hydration in the mean profile of the most distinguishable cases, but a strong hydration in the other profile. It is worth noting that the positions of the minimum of dehydration $(-0.82 \mathrm{ppmv})$ and middle zero point in strong dehydration profile just correspond to upper and lower peaks respectively. For the other strong hydration profile, the positions of the middle zero point and maximum of hydration $(0.85 \mathrm{ppmv})$ also correspond to their peaks respectively. The results in Fig. $6 \mathrm{c}$ and $\mathrm{f}$ of our paper are very similar to the pervious results in Fig. 3a and b of Hervig et al. (2015). In that paper, the strong dehydration and hydration profiles were employed to distinguish the mature and declining state of PMCs.

The general conditions for the $\mathrm{SH}$ is similar as that for the $\mathrm{NH}$. The warmer and drier atmospheric environment in the $\mathrm{SH}$ lead to fewer and dimmer PMCs than in the NH. The mean modulation of the most distinguishable cases shown in Fig. 6d have reached $0.567 \pm 0.206(0.027)$, which is much higher than that of $0.342 \pm 0.175(0.023)$ for the less distinguishable cases. Also, the most distinguishable cases have a slightly greater mean IWC of $47.49 \pm 30.94(3.99) \mathrm{g} \mathrm{km}^{-2}$ and smaller distance of $2.83 \pm 1.02(0.13) \mathrm{km}$ than those of $37.14 \pm 24.03(3.10) \mathrm{g} \mathrm{km}^{-2}$ and $2.36 \pm 0.51(0.07) \mathrm{km}$ for the less distinguishable cases. Although the profiles in Fig. 6e are statistically undistinguished from each other in the region of $-2-2.6 \mathrm{~km}$, the temperatures of the most distinguishable cases are significantly lower than that of the less distinguishable cases at the other altitudes. These differences suggest the possibility that there are still temperature enhancements happening in the profiles of the most distinguishable cases. From Fig. 6f, it can be seen that there are a strong dehydration and a hydration in these two profiles respectively.

Figure 6 does not show the corresponding particle concentrations and radius profiles, since these profiles are statistically undistinguished from each other at most of altitudes because of the wide range of data as well as the lack of sampling in some altitudes. However, all the profiles of means show the same trend as Fig. 5. The mean concentrations profiles have obvious double-layer structure, while the radius profiles present a relatively smooth and monotonic increasing trend without any identified double-layer structure relating to decreasing altitude. In fact, the assembled result in Fig. 6 suggests that the most distinguishable cases are probably double-layer PMCs observed in a growing or mature condition. The temperature enhancement plays an important role and leads to a sharp decrease in particle concentration and hence the formation of the trough. If the temperature enhancement is partly induced by upward GWs, the sedimentation speed can be reduced to some extent. The concentration then increases and the particle grows again because of the colder temperature at the lower peak altitudes. The strong dehydration also indicates that much more water vapour is being transformed into ice crystals, while the less distinguishable cases are probably double-layer PMCs observed in a declining condition. The higher temperature around the trough accompanied by the weakening disturbance on it can promote the sublimation of ice crystals. Also, the strong hydration indicates that much more ice crystals are being sublimated into water vapour.

\subsection{Possible microphysical mechanism}

The most curious thing appears to be the mean effective radius and water vapour residual profiles without any clear double-layer structure. We can consider three extreme hypotheses. The first is that the temperature has suffered from a small-scale GW and a layered structure has formed around the mesopause where ice particle nucleation may take place. According to the general growth-sedimentation theory (Rapp and Thomas, 2006), two initial and individual layers may be formed on the top. If these two layers of ice particles do not interfere with each other during their sedimentation, they can form respective double-layer structures in the $V_{\text {ice }}$ pro- 


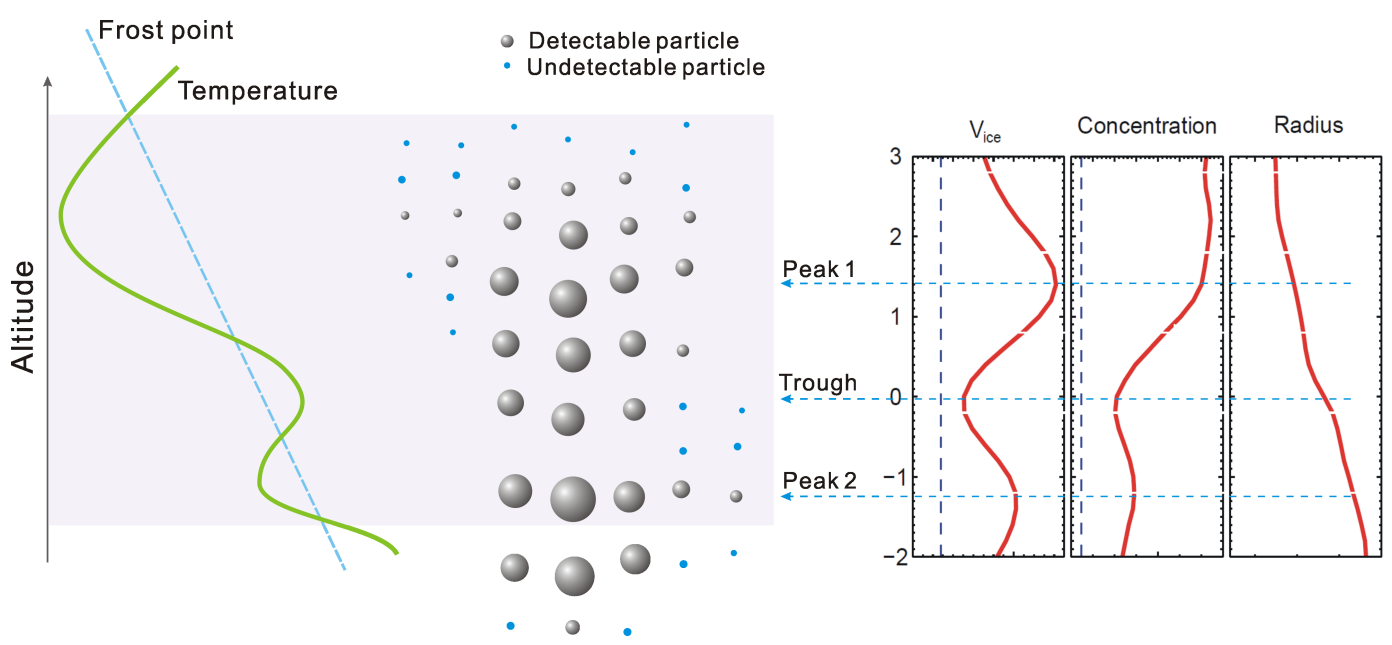

Figure 7. Illustration of the double-layer structure of the PMC particle evolution. Grey solid circles denote particles which are large enough to be detected by SOFIE, while the blue solid circles are undetectable tiny particles. The right panel provides three real mean profiles of double-layer events in the NH derived from Fig. 5.

file as well as concentration and radius profiles. However, the monotone structures in Fig. 5c and f contradict this hypothesis. Secondly, we make another hypothesis in which double layers are evolved from a single peak by encountering a heating event near the peak region like the process of double peaks in airglow. If so, the sublimation of ice particles around the peak would thereby increase the water vapour in this region, which means there will be two peaks on the water vapour residual profiles. However, the shapes of profiles in Fig. 6d and $\mathrm{f}$ are not consistent with our hypothesis. Thirdly, Dubinskii and Popel (2012) give another possibility that the lower half of nucleation particles that first passes through the layer of water vapour sediments, is accelerated, and does not leave water vapour after itself, forming the lower layer. As a result, the other half of particles moves more slowly and form the upper layer. These process well explained the formation of layered structure in the particle concentration profiles, although they did not simulated the particle size profiles and other parameters.

Combining Figs. 5 and 6, we give a reasonable explanation for the formation mechanism of double-layer structures from our point of view. Also, Fig. 7 is a schematic diagram that help to illustrate our interpretation more clearly. Actually, ice particle nucleation takes place at the altitude with the largest saturation ratio around the cloud top of the PMC ( $\sim 4 \mathrm{~km}$ above the trough). The initial nucleation particles, shown as blue solid circles in Fig. 7, are too small to be detected by general optical instruments. A lower temperature may have a larger impact on the increase in particle concentration than the growth of particle size. When these growing particles descend to $\sim 2 \mathrm{~km}$, where an increasing temperature enhancement appears, they begin to sublimate and lead to a decrease in the concentration and $V_{\text {ice. }}$. However, the mean radius still grows and its growth rate becomes slightly faster.
Baumgarten and Fiedler (2008) proposed that the atmosphere is still supersaturated at the peak and to about several hundred metres below the peak, based on their analysis of lower altitude of maximum particle radius rather than peak altitude. From our point of view, there may be another additional reason. Because of the warming temperature, a large number of smaller particles with only $10-15 \mathrm{~nm}$ radius begin to sublimate or become tiny ones with radii of only several nanometres which are too small to be detected by SOFIE, while the other larger particles still exist. This situation can largely reduce the concentration. If the concentration decreases faster than does the $V_{\text {ice }}$, the mean particle radius is still likely to increase as it is a statistical average parameter. Furthermore, coagulation is not likely since, as the particle size increases, the number density decreases but the volume density decreases.

Subsequently, in the region between -1.5 and $0 \mathrm{~km}$ below the trough, the particle concentration increases again. Most of this increase is as a result of the changing temperature gradient caused by the weakening temperature enhancement. However, the mean particle radius is still growing. We infer that the reason for this is the increasing water vapour again derived from the sublimation of small ice particles at the bottom of the upper layer. Some previous studies have pointed out that the existence of such kind of small particles is reasonable (see, e.g., Hultgren and Gumbel, 2014; Berger and von Zahn, 2007; Megner, 2011). Also, the simulation with time series from Dubinskii and Popel (2012) suggests that there are always a few smaller particles falling behind the larger ones from the layer of nucleation. These kinds of smaller particles grow and sediment but remain relatively small because they are in an environment that has been partially depleted of water vapour. When they enter the less supersaturated region at trough altitudes of $-1-1 \mathrm{~km}$, the 
Kelvin effect becomes critical and often leads to their sublimation. In that case, the water from these particles is deposited within the surrounding region and further contributes to an efficient growth of the already existing large particles. The results in Hervig et al. (2015) show that there is considerably increased water vapour existing in the dehydration layer around the bottom of PMCs. Results of Zasetsky et al. (2009) suggest that the particle growth rate increases with increasing temperature if at an unchangeable supersaturation. Also, the accuracy of SOFIE data is high enough that the total uncertainty in effective radius $r_{\mathrm{e}}>10 \mathrm{~nm}$ is less than $15 \%$ (Hervig et al., 2009). Thus, the water vapour from dehydration can be used to produce new small ice particles and make the existing particles stop sublimating and grow larger again. If both the dehydration and production processes are synchronized, there will be no clear bulge in the water vapour residual profile at trough altitudes. Therefore, these synchronous processes produce the lower peak of double-layer structure. When the temperature continues to rise and the water vapour remains constant with decreasing altitude, ice particles will sublimate completely at the bottom of the lower peak. In short, the lower layer is a reproduced layer formed at the bottom of the upper layer. This is the most probable mechanism, at least in our view.

\subsection{Relation to temperature enhancement}

The results of Fig. $6 \mathrm{~b}$ and e are worth testing for the temperature enhancement for every double-layer event. Figure 8 shows a typical example during orbit no. 17323 in the $\mathrm{NH}$ on 30 June 2010. The real temperature profile is shown as the red curve, while the zonal mean temperature profile averaged by all profiles during one day is shown as a blue dashdot curve. There is an obvious temperature disturbance on the real temperature profile compared with the mean profile. The maximum of the warm phase on the real profile is located between the two peaks of $V_{\text {ice }}$ profile, shown as the green curve. However, this disturbance of temperature is likely to be neither a mesosphere inversion layer (MIL) nor the stratosphere temperature enhancement (STE). The MILs are generally observed to last for several hours at a given location and even appear in monthly averaged profiles (Meriwether and Gerrard, 2004; Irving et al., 2014). Although a MIL may appear in a wide region of $50-120 \mathrm{~km}$ in altitude at any time of the year, it is usually observed at the low to mid-latitudes (see, e.g., Schmidlin, 1976; Fritts et al., 1993; Mlynczak et al., 2001). The STE is found in the high-latitude winter, but it only develops spanning $30-50 \mathrm{~km}$ in altitude (see, e.g., Fairlie et al., 1990; Von Zahn et al., 1998). Thus, the disturbance of temperature observed by SOFIE is probably induced by irregular upward GWs, or some dynamic waves with fixed wavelengths or wavenumbers such as tidal and planetary waves, or the energy dissipation due to wave breaking.

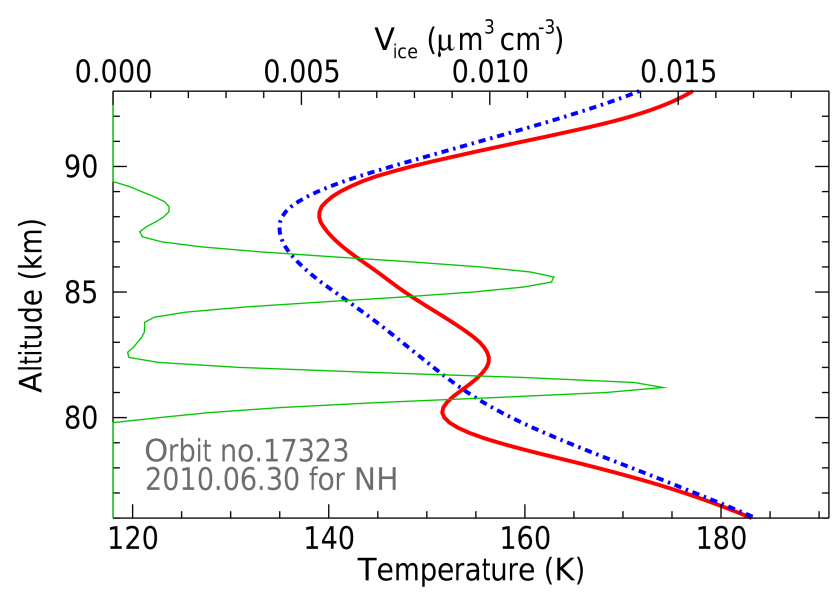

Figure 8. A typical example for demonstrating the temperature enhancement in the event during orbit no. 17323 in the $\mathrm{NH}$ on 30 June 2010. The real temperature profile is shown as the red curve, while the zonal mean temperature profile averaged by all profiles during one day is shown as a blue dash-dot curve. Green curve represent the $V_{\text {ice }}$ profile for this event.

We derive the temperature enhancements from temperature profiles for all double-layer events. The results show that 85.66 and $75.42 \%$ of all double-layer events have maximum temperature enhancements larger than $2 \mathrm{~K}$ for the $\mathrm{NH}$ and $\mathrm{SH}$ respectively. The averaged maximum enhancement is $7.86 \pm$ $3.96(0.15) \mathrm{K}$ for the $\mathrm{NH}$, while it is $6.86 \pm 3.78(0.28) \mathrm{K}$ for the SH. If only the events with altitudes of maximum enhancements located between the two peaks are allowed to be filtered out, the occurrence percentages are reduced to 56.00 and $47.51 \%$ for the NH and SH respectively. These temperature enhancement profiles and corresponding positions of the two peaks are shown in Fig. 9. The $x$ axis denotes event number, arranged by increasing trough altitudes. According to the microphysical mechanism mentioned in Sect. 4.2, the double-layer events shown in Fig. 9 would have close relations with the temperature enhancements. For other events for which maximum enhancement altitudes are not located between their two peaks, the temperature enhancements may still have impact on the double-layer structure. Since both the disturbance phase on temperature profile and the change in double-layer vertical structure depend on time, SOFIE may capture a particular stage in the life cycle of a doublelayer event. For the other events without any enhancement on their temperature profiles, one of the possibilities is that the double-layer event is in a declining stage while the disturbance of temperature is rapidly weakening. Unfortunately, the satellite observation is not capable of providing a local time series of data for our analysis in this work.

\subsection{Relation to GWs}

The latest version of SOFIE data provides the user with GW potential energy (PE) $\left(\mathrm{J} \mathrm{kg}^{-1}\right)$, an indicator of GW intensity, 

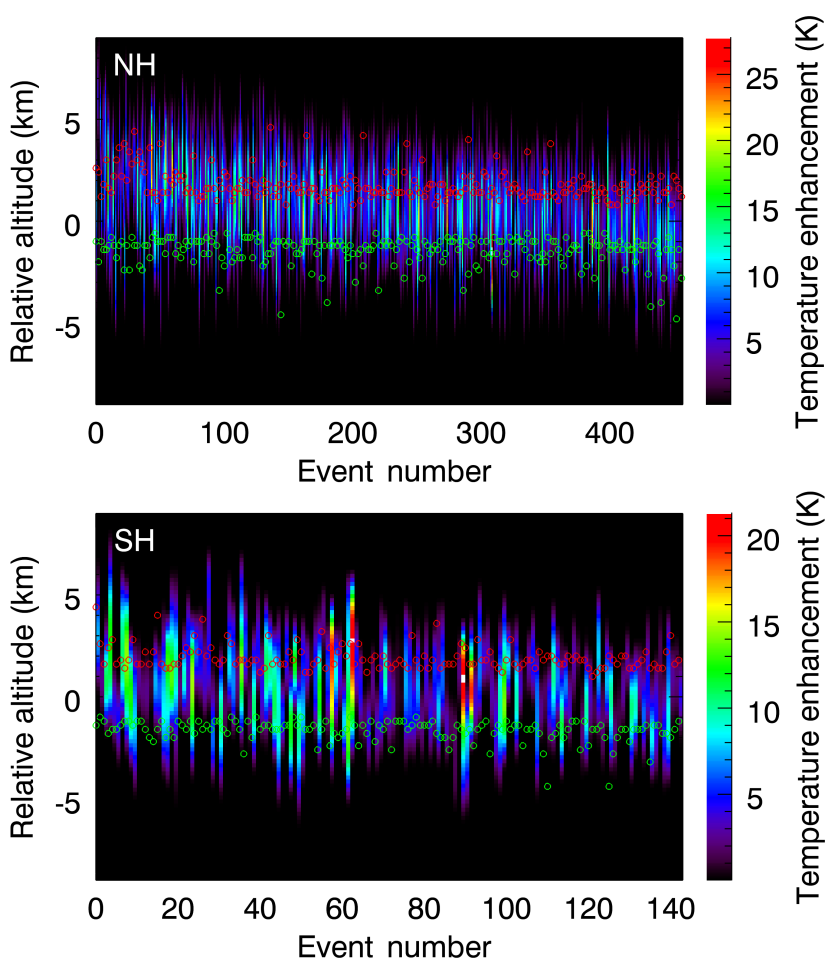

Figure 9. Temperature enhancement distributions for corresponding double-layer events which have maximum temperature enhancements larger than $2 \mathrm{~K}$ locating between their double peaks. Red and green circles denote the positions of upper and lower peaks respectively. All altitudes are aligned to their troughs.

for each temperature profile (Thurairajah et al., 2014; Liu et al., 2014). By means of horizontal harmonic fitting and vertical filtering, three dominant vertical wavelengths of GWs are restricted to between 3 and $30 \mathrm{~km}$. Although these wavelengths are not short enough to analyse the impact on the fine structure of the double-layer, we can still use them to compare the PE distribution for different conditions. Figure 9 shows both the PEs for double-layer events (red) and the corresponding daily mean PEs for PMCs (blue) with regard to the increasing trough altitude the same as Fig. 1. Both types of PEs are averaged over the altitude range of $78-87 \mathrm{~km}$. The $t$ tests are implemented for the two data sets in Fig. 9a and b respectively, and the significances are $7.45 \times 10^{-4}$ for Fig. 9a and 0.044 for Fig. 9b, which indicate statistically differences between their means. From the smoothing curves for the $\mathrm{NH}$ in Fig. 10a, it can be seen that the PEs for double-layer PMCs are smaller and show a gradual decrease compared with the more stable daily mean PEs. The maximum difference between these two curves is more than $25 \%$ near event number 700. For the SH in Fig. 10b, PEs for double-layer PMCs are smaller than the daily mean PEs in the most part, with the maximum difference of $\sim 48 \%$, though they are slightly greater within the range of event numbers 10 to 70 . Then we calculate longitudinal distributions for the occurrence fre-
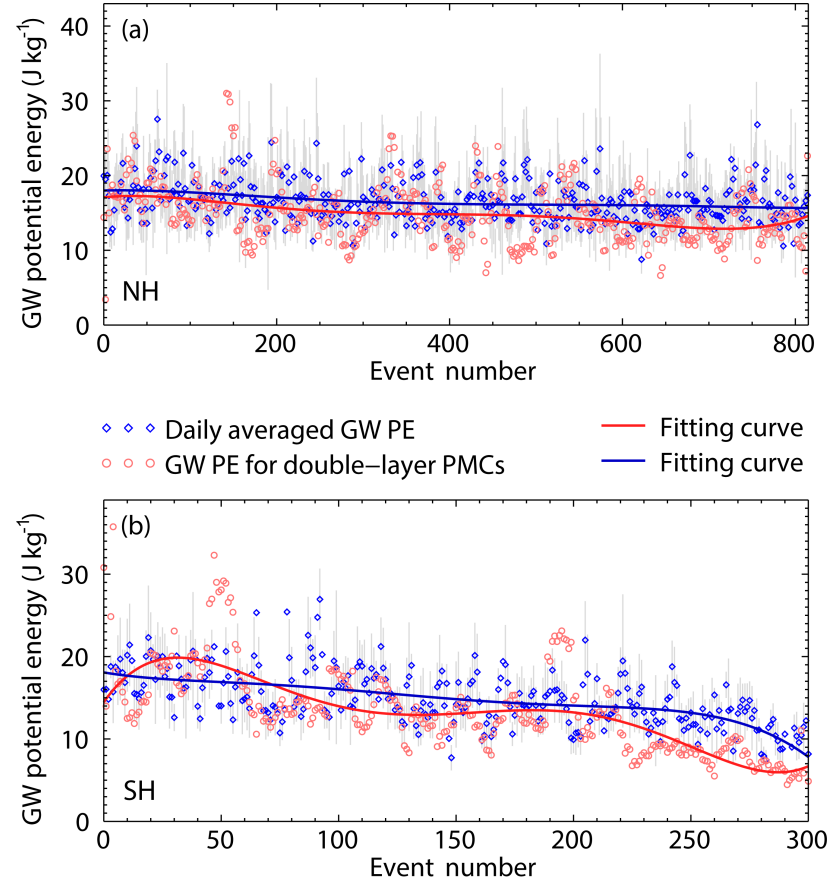

Figure 10. GW potential energy (PE) distributions for double-layer PMCs in the NH (a) and SH (b). Red denotes the corresponding GW PEs to the double-layer PMCs, while blue denotes the daily averaged GW PEs. Scattered circles are smoothed with a window of 10 events, and grey error bars show the standard deviation of the mean. Curves represent the polynomial fitting results.

quencies (OFs) of double-layer PMCs to all observations (red) and all PMC events (green) shown in Fig. 11. While the longitudinal distributions of mean GW PEs (blue) are calculated by averaging the data of all PMC seasons during 20072014 and shown in Fig. 11. Both OFs for the double-layer PMCs are similar to each other for the NH and SH. The most interesting result is that there is a clear anti correlation between the GW PEs and both OFs of double-layer PMCs for both the NH and SH. Separately, the correlation coefficients between GW PEs and OF of double-layer PMCs to all observations are -0.65 for the $\mathrm{NH}$ and -0.61 for the SH. For the OF of double-layer PMCs in all PMC events, the correlation coefficients are -0.71 for the $\mathrm{NH}$ and -0.67 for the $\mathrm{SH}$. From the combination of Figs. 10 and 11, it can be inferred that the double-layer PMC preferentially appears in an environment where the GWs have weaker intensity than normal, at least for the high altitudes $\left(66-83^{\circ}\right)$.

Previous studies have proved that the active intensity of GWs is anti-correlated with the normal PMCs' occurrence frequency (see, e.g., Chandran et al., 2010; Gerrard et al., 1998; Rapp et al., 2002). It is now widely accepted that gravity waves provide the bulk of the momentum forcing that drives the circulation in the MLT which is responsible for the cold summer mesopause $(\sim 90 \mathrm{~km})$. Liu (2000) has shown that GW breaking in the MLT may produce a downward heat 

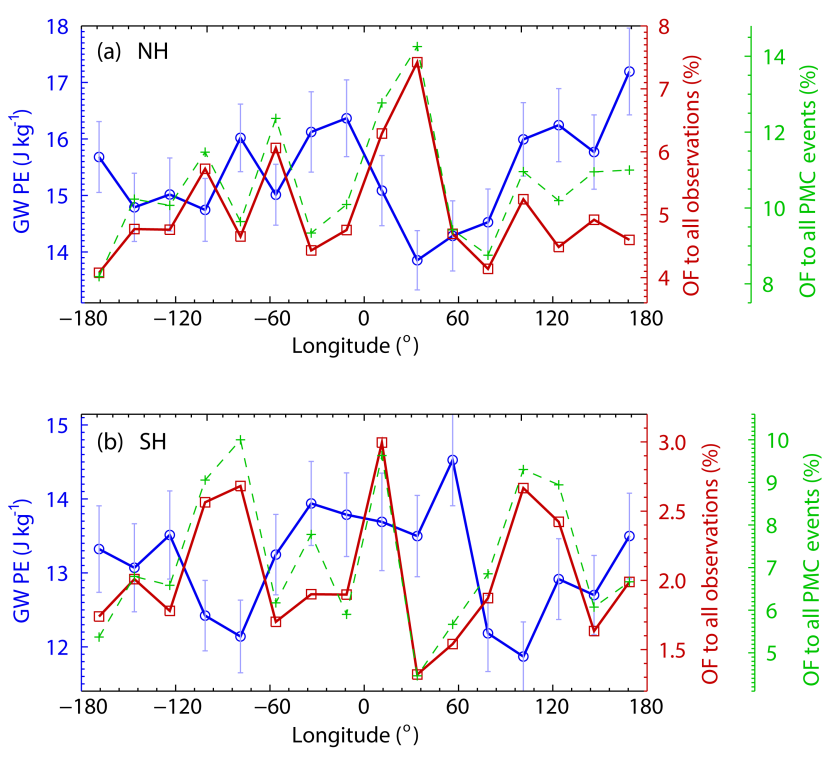

Figure 11. Longitudinal distributions for the occurrence frequencies (OF) of double-layer PMCs to all observations (red) and all PMC events (green) shown in Fig. 10. While the longitudinal distributions of mean GW PEs (blue) are calculated by averaging the data of all PMC seasons during 2007-2014. Error bars show the standard deviation of the mean.

flux, which cools the mesopause region and heats the region immediately below. Chandran et al. (2010) suggest that dissipating AGW can heat the atmosphere at PMC altitudes $(81-84 \mathrm{~km})$ by the adiabatically propagation or by driving a downward heat flux from the breaking altitudes, causing ice sublimation and hence fewer and dimmer PMCs. Our result in Fig. 11 also provides a further associated evidence that the double-layer PMC as one special kind of PMC has the same characteristics of anti-correlation. However, a few studies point out that GWs are important for double-layer production, while their studies do not imply this due to the anticorrelation observed (see, e.g., Kaifler et al., 2013a, b; Rapp et al., 2003; Röttger, 1994). The upward GWs modulate the mean background temperature with height by quasiperiodic alternating warming and cooling phases. The peaks form in the cooling phase region where a certain water vapour saturation temperature is reached, while the troughs form in the warming phases because of the sublimation of ice particles. Our results in Figs. 6, 8 and 9 also provide supplementary evidence that most of the double-layer PMCs have temperature enhancements like the warming phases on their background temperature profiles. Thus, the occurrence of the PMCs with layered structure might be expected to have a positive correlation with the occurrence of GWs. Interestingly, our results in Figs. 10 and 11 just provide another additional limiting condition on the previous studies. The PMCs with layered structure may not be related to all kinds of GWs but rather only the kind with relatively weak intensity. Conversely, the GWs with greater intensity would cause a stronger heat- ing effect at the PMCs' altitudes and hence dissipation of clouds directly, or they would cause a strong cooling effect and therefore enhance the single peak rather than induce a double-layer structure.

\section{Conclusions}

Layered structure in PMCs has been considered as an important indicator for some dynamic processes in the MLT region. We employ the SOFIE data during all PMC seasons between 2007 and 2014 to research the double-layer structures in PMCs. By means of several filter criteria, we find 816 and 301 double-layer PMC events, which correspond to percentages of 10.32 and $7.25 \%$ of total PMC events; the mean distances between two peaks are 3.06 and $2.73 \mathrm{~km}$ for the $\mathrm{NH}$ and $\mathrm{SH}$ respectively. The main peaks with larger $V_{\text {ice }}$ tends to be located above the secondary peak with smaller $V_{\text {ice }}$. Double-layer PMCs almost always have less mean IWC than daily IWC during the core of the season, but they are close to each other at the beginning and the end. The result by averaging over all events shows that the particle concentration has obvious double peaks, while the particle radius exhibits an unexpected monotonic increase with decreasing altitude. By further analysis of the mean background temperature and water vapour residual profiles, we conclude that the lower layer is a reproduced one formed at the bottom of the upper layer. However, 56.00 and $47.51 \%$ of all double-layer PMCs for the $\mathrm{NH}$ and $\mathrm{SH}$ respectively have background temperature enhancements larger than $2 \mathrm{~K}$ located between their double peaks. This indicates that the warm phase of disturbance on the background temperature can make a significant influence on the form of double-layer structures in PMCs. The longitudinal anti-correlation between the GWs PEs and occurrence frequencies of double-layer PMCs suggests that the doublelayer PMCs tend to form in an environment where the GWs have weaker intensities.

There are still other possibilities for forming double-layer structures in PMC. Two different cloud systems advecting within a region of vertical wind shear, or advection transmission by small- or medium-scale waves in the region of PMCs, can also produce a layered structure. These possibilities have not been assessed in this work due to the absence of synchronization data such as background wind, which may affect the advection transport of water vapour. Furthermore, since the sample line-of-sight volume length for SOFIE is about $290 \mathrm{~km}$ long at an altitude of $83 \mathrm{~km}$, the assumption that PMCs spread uniformly in the FOV may produce errors for the inversion algorithm calculated layer by layer. However, the statistical results derived from a large volume of data can significantly reduce this error. In fact, the satellite is not capable of obtaining time series data, which limits our analysis of the dynamic process. Also, if the horizontal resolution is improved and more accurate PMC parameters such as radius and concentration are obtained, the true mechanism 
producing the double (or multiple) PMC layers will be further researched. In future work, we will use a cloud model (e.g. CAMAR) to simulate the process generating doublelayer structures in PMCs by means of the results in this research.

Data availability. The SOFIE PMC data are now available to the public in the form of summary files containing data for each PMC season at http://sofie.gats-inc.com/sofie/index.php.

Acknowledgements. We acknowledge the efforts of the entire AIM development, engineering, science and operations teams. We are also grateful for the support by the National Natural Science Foundation of China (no. 41304124 and 61675165), the Key Project of Research and Development Program (BE2015003) and the Basic Research Project of Jiangsu Province (BK20141480) and National Natural Science Foundation of Shaanxi Province (no. 2016JM1011).

The topical editor, A. J. Kavanagh, thanks two anonymous referees for help in evaluating this paper.

\section{References}

Baumgarten, G. and Fiedler, J.: Vertical structure of particle properties and water content in noctilucent clouds, Geophys. Res. Lett., 35, L10811, doi:10.1029/2007GL033084, 2008.

Baumgarten, G., Chandran, A., Fiedler, J., Hoffmann, P., Kaifler, N., Lumpe, J., Merkel, A., Randall, C. E., Rusch, D., and Thomas, G.: On the horizontal and temporal structure of noctilucent clouds as observed by satellite and lidar at ALOMAR (69N), Geophys. Res. Lett., 39, L01803, doi:10.1029/2011GL049935, 2012.

Berger, U. and von Zahn, U.: Three-dimensional modelling of the trajectories of visible noctilucent cloud particles: An indication of particle nucleation well below the mesopause, J. Geophys. Res., 112, D16204, doi:10.1029/2006JD008106, 2007.

Chandran, A., Rusch, D. W., Merkel, A. W., Palo, S. E., Thomas, G. E., Taylor, M. J., Bailey, S. M., and Russell III, J. M.: Polar mesospheric cloud structures observed from the cloud imaging and particle size experiment on the Aeronomy of Ice in the Mesosphere spacecraft: Atmospheric gravity waves as drivers for longitudinal variability in polar mesospheric cloud occurrence, J. Geophys. Res., 115, D13102, doi:10.1029/2009JD013185, 2010.

Dalin, P., Kirkwood, S., Andersen, H., Hansen, O., Pertsev, N., and Romejko, V.: Comparison of long-term Moscow and Danish NLC observations: statistical results, Ann. Geophys., 24, 28412849, doi:10.5194/angeo-24-2841-2006, 2006.

DeLand, M. T. and Thomas, G. E.: Updated PMC trends derived from SBUV data, J. Geophys. Res., 120, 2140-2166, doi:10.1002/2014JD022253, 2015.

Dubinskii, A. Yu. and Popel, S. I.: Formation and evolution of dusty plasma structures in the ionosphere, JETP Letters, 96, 21-26, doi:10.1134/S0021364012130048, 2012.

Fairlie, T. M., Fisher, D. A., and O'Neill, A.: The development of narrow baroclinic zones and other small-scale structure during simulated major warmings, Q. J. Roy. Meteorol. Soc., 116, 287315, doi:10.1002/qj.49711649204, 1990.

Fogle, B. and Haurwitz, B.: Noctilucent Clouds, Space Sci. Rev., 6, 279-340, 1966.

Fritts, D. C.: Gravity wave saturation in the middle atmosphere a review of theory and observations, Rev. Geophys., 22, 275-308, doi:10.1029/2001RG000106, 1984.

Fritts, D. C., Wang, D.-Y., and Blanchard, R. C.: Gravity wave and tidal structures between 60 and $140 \mathrm{~km}$ inferred from space shuttle re-entry data, J. Atmos. Sci., 50, 785-806, doi:10.1175/15200469(1993)050<0837:GWATSB>2.0.CO;2, 1993.

Gao, H., Xu, J., Ward, W., Smith, A. K., and Chen, G. M.: Doublelayer structure of $\mathrm{OH}$ dayglow in the mesosphere, J. Geophys. Res., 120, 5778-5787, doi:10.1002/2015JA021208, 2015.

Gerrard, A. J., Kane, T. J., and Thayer, J. P.: Noctilucent clouds and wave dynamics: Observations at Sondrestrom, Greenland, Geophys. Res. Lett., 25, 2817-2820, doi:10.1029/98GL02107, 1998.

Gordley, L., Burton, J., Marshall, B. T., McHugh, M., Deaver, L., Nelsen, J., Russell, J. M., and Bailey, S.: High precision refraction measurements by solar imaging during occultation: results from SOFIE, Appl. Opt., 48, 4814-4825, doi:10.1364/AO.48.004814, 2009.

Hervig, M. E. and Stevens, M. H.: Interpreting the 35 year SBUV PMC record with SOFIE observations, J. Geophys. Res., 119, 12689-12705, doi:10.1002/2014JD021923, 2014.

Hervig, M. E., Gordley, L. L., Stevens, M. H., Russell III, J. M., Bailey, S. M., and Baumgarten, G.: Interpretation of SOFIE PMC measurements: Cloud identification and derivation of mass density, particle shape, and particle size, J. Atmos. Sol.-Terr. Phy., 71, 316-330, doi:10.1016/j.jastp.2008.07.009, 2009.

Hervig, M. E., Siskind, D. E., Stevens, M. H., and Deaver, L. E.: Inter-hemispheric comparison of PMCs and their environment from SOFIE observations, J. Atmos. Sol.-Terr. Phy., 104, 285298, doi:10.1016/j.jastp.2012.10.013, 2013.

Hervig, M. E., Siskind, D. E., Bailey, S. M., and Russell III, J. M.: The influence of PMCs on water vapour and drivers behind PMC variability from SOFIE observations, J. Atmos. Sol.-Terr. Phy., 132, 124-134, doi:10.1016/j.jastp.2015.07.010, 2015.

Hill, R. J., Gibson-Wilde, D. E., Werne, J. A., and Fritts, D. C.: Turbulence-induced fluctuations in ionization and application to PMSE, Earth Planet Space, 51, 499-513, doi:10.1186/BF03353211, 1999.

Hoffmann, P., Rapp, M., Serafimovich, A., and Latteck, R.: On the occurrence and formation of multiple layers of polar mesosphere summer echoes, Geophys. Res. Lett., 32, L05812, doi:10.1029/2004GL021409, 2005.

Hultgren, K. and Gumbel, J.: Tomographic and spectral views on the lifecycle of polar mesospheric clouds from Odin/OSIRIS, J. Geophys. Res.-Atmos., 119, 14129-14143, doi:10.1002/2014JD022435, 2014.

Hoffmann, P., Rapp, M., Fiedler, J., and Latteck, R.: Influence of tides and gravity waves on layering processes in the polar summer mesopause region, Ann. Geophys., 26, 4013-4022, doi:10.5194/angeo-26-4013-2008, 2008.

Hultgren, K. and Gumbel, J.: Tomographic and spectral views on the lifecycle of polar mesospheric clouds from Odin/OSIRIS, J. Geophys. Res.-Atmos., 119, 14129-14143, doi:10.1002/2014JD022435, 2014. 
Irving, B. K., Collins, R. L., Lieberman, R. S., Thurairajah, B., and Mizutani, K.: Mesospheric Inversion Layers at Chatanika, Alaska $\left(65^{\circ} \mathrm{N}, 147^{\circ} \mathrm{W}\right)$ : Rayleigh lidar observations and analysis, J. Geophys. Res., 119, 11235-11249, doi:10.1002/2014JD021838, 2014.

Kaifler, N., Baumgarten, G., Fiedler, J., and Lübken, F.-J.: Quantification of waves in lidar observations of noctilucent clouds at scales from seconds to minutes, Atmos. Chem. Phys., 13, 1175711768, doi:10.5194/acp-13-11757-2013, 2013a.

Kaifler, N., Baumgarten, G., Klekociuk, A. R., Alexander, S. P., Fiedler, J., and Lubken, F.-J.: Small scale structures of NLC observed by lidar at $69^{\circ} \mathrm{N} / 69^{\circ} \mathrm{S}$ and their possible relation to gravity waves, J. Atmos. Sol.-Terr. Phy., 104: 244-252, doi:10.1016/j.jastp.2013.01.004, 2013b.

Klostermeyer, J.: A height and time dependent model of polar mesosphere summer echoes, J. Geophys. Res., 102, 6715-6727, doi:10.1029/96JD03652, 1997.

Li, H., Wu, J., and Zhou, Z.: The formation of multiple layers of ice particles in the polar summer mesopause region, Ann. Geophys., 34, 117-122, doi:10.5194/angeo-34-117-2016, 2016.

Liu, G. and Shepherd, G. G.: Perturbed profiles of oxygen nightglow emissions as observed by WINDII on UARS, J. Atmos. Sol.-Terr. Phy., 68, 1018-1028, doi:10.1016/j.jastp.2005.12.004, 2006.

Liu, H. L.: Temperature changes due to gravity wave saturation, J. Geophys. Res., 105, 12329-12336, doi:10.1029/2000JD900054, 2000.

Liu, X., Yue, J., Xu, J., Wang, L., Yuan, W., Russell III, J. M., and Hervig, M. E.: Gravity wave variations in the polar stratosphere and mesosphere from SOFIE/AIM temperature observations, J. Geophys. Res., 119, 7368-7381, doi:10.1002/2013JD021439, 2014.

Liu, X., Yue, J., Xu, J., Yuan, W., Russell III, J. M., and Hervig, M. E.: Five-day waves in polar stratosphere and mesosphere temperature and mesospheric ice water measured by SOFIE/AIM, J. Geophys. Res., 120, 3872-3887, doi:10.1002/2015JD023119, 2015.

Lübken, F.-J., Zecha, M., Höffner, J., and Röttger, J.: Temperatures, polar mesosphere summer echoes, and noctilucent clouds over Spitsbergen $\left(78^{\circ} \mathrm{N}\right)$ : J. Geophys. Res., 109, D11203, doi:10.1029/2003JD004247, 2004.

Marshall, B. T., Deaver, L. E., Thompson, R. E., Gordley, L. L., McHugh, M. J., Hervig, M. E., and Russell III, J. M.: Retrieval of temperature and pressure using broadband solar occultation: SOFIE approach and results, Atmos. Meas. Tech., 4, 893-907, doi:10.5194/amt-4-893-2011, 2011.

McLandress, C., Shepherd, G. G., and Solheim, B. H.: Satellite observations of thermospheric tides: results from the Wind Imaging Interferometer on UARS, J. Geophys. Res., 101, 4093-4114, doi:10.1029/95JD03359, 1996.

Megner, L.: Minimal impact of condensation nuclei characteristics on observable mesospheric ice properties, J. Atmos. Sol.-Terr. Phy., 73, 2184-2191, doi:10.1016/j.jastp.2010.08.006, 2011.

Melo, S. M. L., Lowe, R. P., and Russell, J. P.: Double-peaked hydroxyl airglow profiles observed from WINDII/UARS, J. Geophys. Res., 105, 12397-12403, doi:10.1029/1999jd901169, 2000 .
Meriwether, J. W. and Gerrard, A. J.: Mesosphere inversion layers and stratosphere temperature enhancements, Rev. Geophys., 42, RG3003, doi:10.1029/2003RG000133, 2004.

Mlynczak, M. G., Morgan, F., Yee, J.-H., Espy, P., Murtagh, D., Marshall, B., and Schmidlin, F.: Simultaneous measurements of the $\mathrm{O} 2(1 \mathrm{D})$ and $\mathrm{O} 2(1 \mathrm{~S})$ airglows and ozone in the daytime mesosphere, Geophys. Res. Lett., 28, 999-1002, doi:10.1029/2000GL012423, 2001.

Pertsev, N., Dalin, P., Perminov, V., Romejko, V., Dubietis, A., Balčiunas, R., Černis, K., and Zalcik, M.: Noctilucent clouds observed from the ground: sensitivity to mesospheric parameters and long-term time series, Earth Planets Space, 66, 98, doi:10.1186/1880-5981-66-98, 2014.

Pertsev, N., Dalin, P., and Perminov, V.: Influence of semidiurnal and semimonthly lunar tides on the mesopause as observed in hydroxyl layer and noctilucent clouds characteristics, Geomagn. Aeronomy, 55, 811-820, doi:10.1134/S0016793215060109, 2015.

Rapp, M. and Thomas, G. E.: Modeling the microphysics of mesospheric ice particles: Assessment of current capabilities and basic sensitivities, J. Atmos. Sol.-Terr. Phy., 68, 715-744, doi:10.1016/j.jastp.2005.10.015, 2006.

Rapp, M., Lübken, F.-J., Müllemann, A., Thomas, G. E., and Jensen, E. J.: Small-scale temperature variations in the vicinity of NLC: Experimental and model results, J. Geophys. Res., 107, 4392, doi:10.1029/2001JD001241, 2002.

Rapp, M., Lübken, F.-J., and Blix, T.: The role of charged ice particles in the creation of PMSE: A review of recent developments, Adv. Space Res., 31, 2033-2043, doi:10.1016/S02731177(03)00226-6, 2003.

Romejko, V. A., Dalin, P. A., and Pertsev, N. N.: Forty years of noctilucent cloud observations near Moscow: database and simple statistics, J. Geophys. Res., 108, 8443, doi:10.1029/2002JD002364, 2003.

Röttger, J.: Middle atmosphere science middle atmosphere and lower thermosphere processes at high latitudes studied with the EISCAT radars, J. Atmos. Sol.-Terr. Phy., 56, 1173-1195, doi:10.1016/0021-9169(94)90056-6, 1994.

Russell III, J. M., Bailey, S. M., Gordley, L. L., Rusch, D. W., Horányi, M., Hervig, M. E., Thomas, G. E., Randall, C. E., Siskind, D. E., Stevens, M. H., Summers, M. E., Taylor, M. J., Englert, C. R., Espy, P. J., McClintock, W. E., and Merkel, A. W.: The Aeronomy of Ice in the Mesosphere (AIM) mission: Overview and early science results, J. Atmos. Sol.-Terr. Phy., 71, 289-299, doi:10.1016/j.jastp.2008.08.011, 2009.

Rüster, R., Röttger, J., Schmidt, G., Czechowsky, P., and Klostermeyer, J.: Observations of mesospheric summer echoes at VHF in the polar cap region, Geophys. Res. Lett., 28, 1471-1474, doi:10.1029/2000GL012077, 2001.

Schmidlin, F. J.: Temperature inversions near 75 km, Geophys. Res. Lett., 3, 173-176, doi:10.1029/GL003i003p00173, 1976.

Stevens, M. H., Deaver, L. E., Hervig, M. E., Russell III, J. M., Siskind, D. E., Sheese, P. E., Llewellyn, E. J., Gattinger, R. L., Höffner, J., and Marshall, B. T.: Validation of upper mesospheric and lower thermospheric temperatures measured by the Solar Occultation for Ice Experiment, J. Geophys. Res., 117, D16304, doi:10.1029/2012JD017689, 2012.

Thomas, G. E., Olivero, J. J., Jensen, E. J., Schroeder, W., and Toon, O. B.: Relation between increasing methane and the pres- 
ence of ice clouds at the mesopause, Nat. Mater., 338, 490-492, doi:10.1038/338490a0, 1989

Thurairajah, B., Bailey, S. M., Cullens, C. Y., Hervig, M. E., and Russell III, J. M.: Gravity wave activity during recent stratospheric sudden warming events from SOFIE temperature measurements, J. Geophys. Res., 119, 8091-8103, doi:10.1002/2014JD021763, 2014.

Von Zahn, U., Fiedler, J., Naujokat, B., Langematz, U., and Krueger, K.: A note on record-high temperatures at the northern polar stratopause in winter 1997/98, Geophys. Res. Lett., 25, 41694172, doi:10.1029/1998GL900091, 1998.
Zasetsky, A. Y., Petelina, S. V., Remorov, R., Boone, C. D., Bernath, P. F., and Llewellyn, E. J.: Ice particle growth in the polar summer mesosphere: Formation time and equilibrium size, Geophys. Res. Lett., 36, L15803, doi:10.1029/2009GL038727, 2009. 